\title{
VIEWPOINT
}

\section{Fat infiltration in the heart}

\author{
Liron Pantanowitz
}

Current teaching is that fatty infiltration into the myocardium (lipomatosis or cor adiposum) rarely affects cardiac function. This may not be entirely true. Rupture during acute myocardial infarction has certainly been shown to be more common in the fatty heart. ${ }^{1}$ Fat infiltrating in the region of the conduction system is responsible for causing sudden death. ${ }^{2}$ Furthermore, it is possible for lipomatous hypertrophy in the heart to even undergo malignant transformation. ${ }^{3}$ Since fat is a normal constituent of the heart, it remains undefined as to exactly how much, and in which locations, one considers fatty infiltration to be pathological. Whether fat extends into the myocardium from subepicardial stores, normally increased with aging and obesity, or arises de novo from pluripotential interstitial cells or cardiac myocytes, is also undetermined. The distinction is important if fat present in the myocardium were to signify prior episodes of hypoxia, during which intracellular lipids no longer able to be metabolised by mitochondria get extruded and phagocytosed. ${ }^{4}$ Transdifferentiation of cardiac muscle into mature adipocytes has indeed been described in association with cardiomyopathy. ${ }^{6}$ This transdifferentiation has been proposed as a possible pathogenetic mechanism for arrhythmogenic right ventricular cardiomyopathy. ${ }^{6}$

The mechanism by which fatty infiltration promotes arrhythmogenicity and/or causes sudden death has never been well addressed. Infiltrating fat may provoke automaticity, and produce atrophy and degeneration of adjacent myocardial cells, ${ }^{7}$ or separate the myocardial cells, thereby reducing the number of sites or the area of intercellular communications. Fat deposition in the heart has been described as a complication in long term parenteral nutrition. ${ }^{8}$ Substantial evidence also exists showing that an excess of certain free fatty acids can induce arrhythmias. ${ }^{9}$ The coexistence of refractory atrial arrhythmias and lipomatous hypertrophy of the interatrial septum is well known. ${ }^{10}$ Right ventricular dysplasia, in which a congenitally absent myocardium of the right ventricle may be partially or completely replaced by adipose and fibrous tissue, also carries the risk of sudden death from arrhythmias. ${ }^{11}$ The mechanism is probably related to the localised lipomatous transformation causing an actual delay in the intraventricular transmission of impulses, with the subsequent development of re-entrant ventricular arrhythmias.

Fatty infiltration of the myocardium is usually an incidental intraoperative or necropsy finding. Most publications dealing with fatty infiltration in the heart have accordingly been largely limited either to retrospective postmortem studies or individual case reports. With advanced radiological and echocardiography techniques it is now possible to identify myocardial fat infiltration antemortem. ${ }^{12}$ In addition to their diagnostic utility, these high quality imaging techniques can provide a noninvasive means for prospectively following patients. They may also help to localise and quantitatively characterise normal myocardial fat $^{13}$ as well as compare the prevalence of myocardial fatty infiltration in vivo to prior necropsy series. Studies correlating radiological findings with biopsy, transplant or postmortem specimens may aid in further delineating the clinicopathological significance of myocardial fat infiltration.

1 Roberts WC, Roberts JD. The floating heart or the heart too fat to sink: analysis of 55 necropsy patients. Am $\mathcal{F}$ Cardiol 1983;52:1286-9.

2 Bharati S, Lev M. Cardiac conduction system involvement in sudden death of obese young people. Am Heart $\mathcal{F} 1996$; 129:273-81.

3 Castleman B, McNeely BU. Case records of the Massachusetts General Hospital (case 43-1971). Liposarcoma of interatrial septum and both atria. N Engl f Med 1971;285: 1016-23.

4 Bilheimer DW, Buja LM, Parkey RW, et al. Fatty acid accumulation and abnormal lipid deposition in peripheral and border zones of experimental myocardial infarcts. $7 \mathrm{Nucl}$ Med 1978;19:276-83.

5 Rosonowski A, Ruzyllo W, Chrzanowski M. Ultrastructural aspect of subendocardial fat cells accumulation. Zentralbl allg Pathol $1986 ; 131: 349-355$.

6 d'Amati G, di Gioia CRT, Giordano C, et al. Myocyte transdifferentiation. A possible pathogenetic mechanism
thente for arrhythmogenic right ventricular cardiomyopathy. Arch Pathol Lab Med 2000;124:287-90.

7 Page DL. Lipomatous hypertrophy of the cardiac interatrial septum: its development and probable clinical significance. Human Pathol 1970;1:151-63.

8 Beau P, Michel P, Coisne D, et al. Lipomatous hypertrophy of the cardiac interatrial septum: an unusual complication Parenter Enteral Nutr 1991;15:659-62.

9 Soloff LA. Arrhythmias following infusions of fatty acids. Am Heart $\mathcal{f}$ 1970; 80:671-674.

10 Reyes CV, Jablokow VR. Lipomatous hypertrophy of the cardiac interatrial septum. A report of 38 cases and review of the literature. Am F Clin Pathol 1979; 72:785-788.

11 Fornes P, Ratel S, Lecomte D. Pathology of arrhythmogenic right ventricular cardiomyopathy/dysplasia - an autopsy study of 20 forensic cases. F Forensic Sci 1998; 43:777-783.

12 Kriegshauser JS, Julsrud PR, Lund JT. MR imaging of fat in and around the heart. Am f Roentgenol 1990; 155:271-4.

13 Broderick LS, Conces DJ Jr, Tarver RD. CT evaluation of normal interatrial fat thickness. F Comput Assist Tomogr 1996; 20:950-3. 